\title{
Nucleic Acid Amplification using Recombinase Polymerase: Enzymatic Approach
}

\section{Norah Abukhalid and Manoj K Pastey*}

Department of Biomedical Sciences, Division of Health Sciences, Oregon State University, Corvallis, Oregon, USA

${ }^{*}$ Corresponding author: Pastey MK, Department of Biomedical Sciences, Division of Health Sciences, Oregon State University, Corvallis, Oregon, USA, Tel: 5417373940; E-mail: manoj.pastey@oregonstate.edu

Received date: Feb 02, 2017, Accepted date: Feb 16, 2017, Published date: Feb 23, 2017

Copyright: (c) 2017 Abukhalid N, et al. This is an open-access article distributed under the terms of the Creative Commons Attribution License, which permits unrestricted use, distribution, and reproduction in any medium, provided the original author and source are credited.

\begin{abstract}
Rapid detection of infections is crucial for the prevention of infectious disease outbreaks, development of antimicrobial drugs and biodefense. When considering a diagnostic test the most important considerations are rapidity, ease of use, portability, specificity and sensitivity. Recently developed isothermal recombinase polymerase amplification (RPA) technology has been shown in many publications to be the most sensitive and effective for determining infections, require no sophisticated and expensive equipment, and is suitable for point-of-care field applications. Here we have described our viewpoints with regard to RPA technology's suitability and usage in resource poor settings, its advantages and limitations. We have also developed a lateral flow assay to detect all serotypes of dengue virus following RPA procedure, demonstrating its suitability for field applications. We believe our suggestions may help in improving RPA procedures and may also help in transitioning to clinical applications.
\end{abstract}

Keywords: Recombinase polymerase amplification (RPA); Diagnostic assays; Isothermal amplification

\section{Introduction}

Rapid diagnostic methods are important for early detection of infectious pathogens, which helps making the required intervention easier at the appropriate time [1]. In addition, it is essential for epidemiological purposes, like: serotypes categorization and surveillance based studies.

In 1985 PCR was first introduced and made a huge impact on both clinical and research fields [2]. The specificity and sensitivity of PCR made it popular [3]. However, technology development went beyond that to include 2 extra features, which are simplicity and feasibility. To this end, Recombinase polymerase amplification (RPA) was introduced in 2006 [4]. As an isothermal technique, the implementation of RPA will facilitate the diagnostics usage especially in resources poor areas.

\section{Concept}

RPA is an isothermal (heat independence) nucleic acid amplification technique [5]. Using a combination of 3 enzymes the amplification will be achieved within 20 minutes. The enzymes are: recombinase, single strand binding protein (SSB) and strand displacing DNA polymerase. In case of RNA template, an additional enzyme will be needed which is reverse transcriptase.

Distinctively, each enzyme will perform a major function that leads to amplification. Recombinase scans the oligonucleotides (primers) to form a nucleoprotein filament, which will bind to the complementary sequence (Template). Therefore, the primers should be designed with certain considerations. Single strand binding protein stabilizes the formed nucleoprotein filament in its corresponding position. Lastly, strand displacing DNA polymerase makes the extension of each strand, generating many copy numbers of the nucleic acid [6].

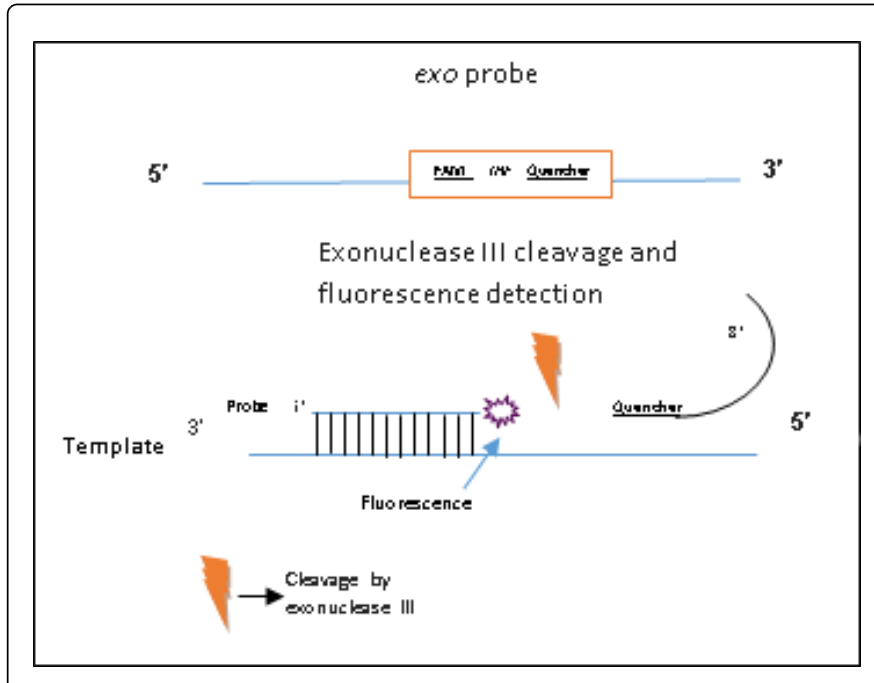

Figure 1: Real-time detection using exo probe8. The principle of the exo probe is that fluorophore (FAM), Tetrahydrofuran (THF) and Quencher are in close proximity to one another (with only 1-5 intervening nucleotides). The THF residue is cleaved by Exonuclease III only when the probe is bound to its target. This cutting step separates the fluorophore and quencher and generates a fluorescence signal. 


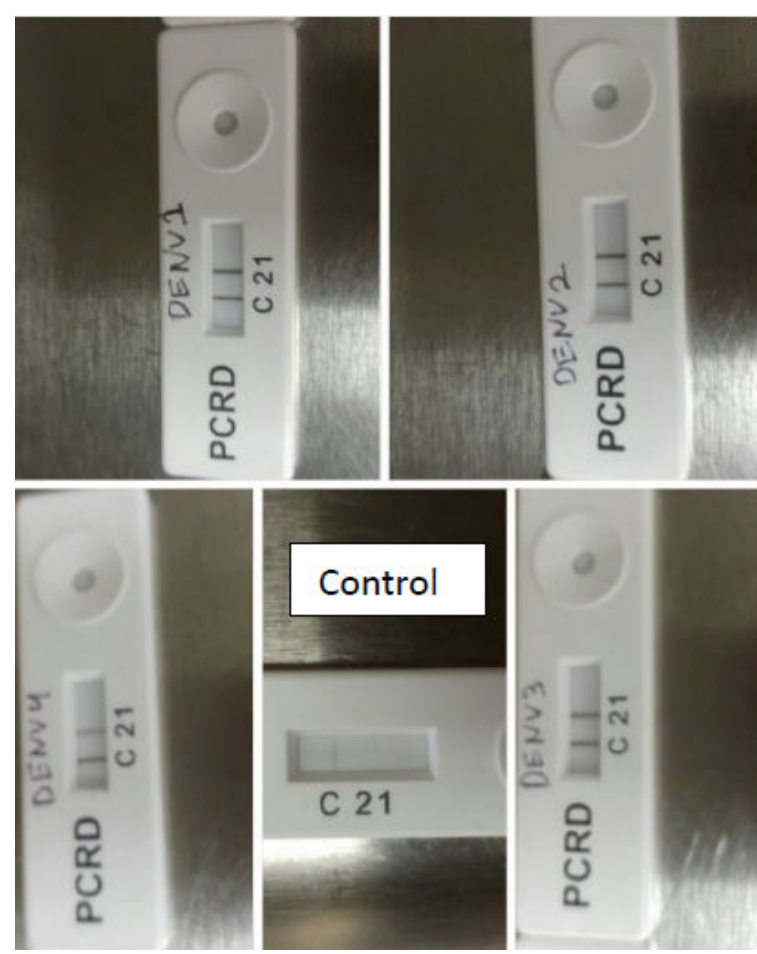

Figure 2: LFA assay: DENV's viruses detection using primers that made from conserved region [9], to detect all DENVs subtypes. Each device labelled with corresponding subtypes beside a negative control. The lateral flow assay has three reaction lines: C, control; 1 , detects DIG/Biotin-labelled amplicons (not used here); 2, detects FAM/Biotin-labelled amplicons.

Detection of amplified product could be achieved using 2 main formats either fluorescence format or non-fluorescence formats [7]. In the fluorescence method, it is possible to get real time monitoring of the amplicon (amplified nucleic acid) using exo probes (Figure 1). Fluorescence signal is a perfect reflection of the reaction status i.e. signals starting point, positive control reading and negative control result, all are indicator used to judge the quality of the assay. Nonfluorescence format involves primers modification for the purpose of amplicon detection (qualitative) [8]. It includes but not limited to Lateral Flow Assay (LFA), Loop mediated isothermal amplification (LAMP), and Lateral Flow strips (LFS). LFA employs 2 types of antibodies: anti-FAM and anti-Biotin for colorimetric detection format (Table 1). Our lab used LFA to detect dengue viruses (DENVs) with universal pan-DENV forward and reverse primer set, which had substitution of the 5' ends with FAM and Biotin, respectively (Figure 2).

\section{Advantages}

RPA as a recently introduced technology has various strength points. First, short reaction time (about 20 minutes) is a unique feature and important for rapid diagnosis of many pathogens. Second, feasibility and the ability to conduct the assay without the need of highly expensive settings make it suitable for Point of Care use and in resource poor setting. Third, flexibility of the test to accommodate varied targets as many kits were developed for different target detection (Table 2).

\begin{tabular}{|c|c|c|}
\hline Feature/Technology & $\begin{array}{l}\text { Polymerase chain } \\
\text { reaction (PCR) }\end{array}$ & $\begin{array}{l}\text { Recombinase } \\
\text { Polymerase } \\
\text { Amplification (RPA) }\end{array}$ \\
\hline Principle & $\begin{array}{l}\text { Thermal nucleic acid } \\
\text { amplification technique, } \\
\text { consist of } 3 \text { steps: } \\
\text { denaturation, annealing } \\
\text { and elongation at } \\
\text { different temperatures. }\end{array}$ & $\begin{array}{l}\text { Isothermal nucleic acid } \\
\text { amplification technique, } \\
\text { consist of } 3 \text { enzymes: } \\
\text { recombinase, single } \\
\text { strand binding protein } \\
\text { (SSB) and strand } \\
\text { displacing } \\
\text { polymerase. }\end{array}$ \\
\hline Specificity and Sensitivity & $\begin{array}{l}\text { Specificity/low, the } \\
\text { amplicon may lose its } \\
\text { specificity from over- } \\
\text { amplification (above } 40 \\
\text { cycles). } \\
\text { Sensitivity/high, because } \\
\text { the reaction take place } \\
\text { under highly controlled } \\
\text { parameters. }\end{array}$ & $\begin{array}{l}\text { Specificity/high, because } \\
\text { the amplification is based } \\
\text { on specific binding site } \\
\text { with relatively long } \\
\text { primers. } \\
\text { Sensitivity/low, because } \\
\text { of the non-specific } \\
\text { binding with non- } \\
\text { homologous sequence } \\
\text { identity of the primers } \\
\text { and probe with the } \\
\text { closely related negative } \\
\text { control targets }\end{array}$ \\
\hline Convenience & $\begin{array}{l}\text { Needs many steps with } \\
\text { costly equipment. }\end{array}$ & $\begin{array}{l}\text { Rapid procedures can be } \\
\text { done with cheap } \\
\text { resources. }\end{array}$ \\
\hline Detection formats & Fluorescence & $\begin{array}{l}\text { Fluorescence } \\
\text { Lateral flow }\end{array}$ \\
\hline
\end{tabular}

Table 1: Comparison between gold standard amplification technique (PCR) and modern technique (RPA).

\begin{tabular}{|l|l|l|l|}
\hline Kits name & Target & $\begin{array}{l}\text { Detection } \\
\text { Probe }\end{array}$ & Application \\
\hline Basic & DNA & NO & Herpes simplex viruses \\
\hline Basic RT & RNA & NO & Dengue virus \\
\hline Exo & DNA & YES & Parvoviruses, Salmonella \\
\hline Exo RT & RNA & YES & Zika virus \\
\hline RT is reverse transcriptase
\end{tabular}

Table 2: TwisDx is the exclusive owner and producer of RPA. It provides a variety of kits, which can adapt to different targets [8].

\section{Limitations and Suggestions}

RPA has some limitations related to its usage outside the research setting:

First: non-specific binding of recombinase enzyme may lead to false positive. Suggestion: get the reaction enzymes separately. So, recombinase should be mixed first with primers only (Specific binding) then template should be added followed by the remaining two enzymes (SSB and Polymerase). Mixing the primers with the template before adding any enzymes is a common mistake. The high amplification signal could be interpreted as a contamination. Therefore, the usage of negative control as an indicator of the reaction environment is 
significant. Negative control should yield a straight signal (no amplification) in the absence of contamination [9].

Second: Instant amplification after mixing the reagents means loss of early data. Suggestion: the enzymes work perfectly at room temperature, which means amplification starts immediately after mixing. So, make sure to hold the tubes in relatively low temperature while mixing the reagents in order to avoid the early beginning of the reaction.

Third: the false amplification of negative control samples. Negative controls are other targets similar in feature to the original target. For example: in case of Zika virus, the usage of other related RNA viruses like Dengue viruses would be considered as negative controls. The negative control should give no amplification at all. There are reports that illustrate the non-specific binding of the negative control in RPA4 [9], with non-homologous sequence identity of the primers and probe with the negative control targets. Suggestion: dilute the template used for negative control to low copy numbers ( 50 or lower) to achieve expected result (no amplification) as an over concentrated template may lead to false positive.

\section{Conclusion}

A decade ago RPA was introduced and many papers have been published about it. Most of the published papers show the usage of RPA in the research setting and so far has not been transitioned to the clinical field. I think RPA may work perfectly in clinical setting after carefully optimizing parameters from clinical samples, in which the various inhibitors of RPA reaction is difficult to control. RPA with modifications such as, increasing the specificity and adjusting the enzymes temperature to control the starting point of the reaction would make it suitable for clinical usage.

\section{References}

1. Flint S, Lynn E, Vincent R, Glenn R, Anna-Marie S (2015) Principles of virology/Volume 2. (4thedn); ASM PRESS, Waukegan IL.

2. Gregory S (2000) Diagnostic Virology. Oxford Journals 31:739-751.

3. Olaf P, Niall A (2007) Biochemical solutions for portable nucleic acid testing. Electronics meets biology 1: 38-41.

4. Abd El WA, Sanabani SS, Faye O, Pessoa R, Patriota JV, et al. (2016) Rapid molecular detection of Zika virus in urine using the recombinase polymerase amplification assay. Bio RXIV.

5. Hosam Z, Mahmoud ES (2014) Recombinase polymerase amplification as a promising tool in hepatitis $\mathrm{C}$ virus diagnosis. World J Hepatol 6: 916-922.

6. Boyle D, McNerney R, Teng Low H, Leader B, Pérez-Osorio A, et al. (2014) Rapid detection of Mycobacterium tuberculosis by recombinase polymerase amplification. PLoS One 9: 1-9.

7. Meagan AP, Aimee R, Ling J, Manoj P (2016) Rapid detection of cyprinid herpesvirus 3 in latently infected koi by recombinase polymerase amplification. J Aquat Anim Health 28: 173-180.

8. Rana D, Gale S, Maurice B, Michel B (2016) Recombinase polymerase amplification for diagnostic applications. Clin Chem 62: 947-958.

9. Boon-Teong T, Sing-Sin S, Kim-Kee T, Mohammed D, Meng-Hooi S, et al. (2015) Early detection of dengue virus by use of reverse transcriptionrecombinase polymerase amplification. J Clin Microbiol 53: 830-837. 